\title{
ANÁLISE DA PRODUÇÃO CIENTÍFICA EM DISSERTAÇÕES E TESES COM FOCO NO FUNCIONAMENTO DAS SALAS DE RECURSOS
}

\author{
ANÁLISIS DE LA PRODUCCIÓN CIENTÍFICA EN LA TESIS SE CENTRÓ EN \\ LA OPERACIÓN DE SALAS DE RECURSOS
}

\section{ANALYSIS OF SCIENTIFIC PRODUCTION IN DISSERTATIONS AND THESES WITH FOCUS ON RESOURCE ROOMS OPERATION}

\author{
Aline Costa FANTINATO ${ }^{1}$ \\ Enicéia Gonçalves MENDES ${ }^{2}$
}

RESUMO: O presente trabalho visou contribuir com as investigações do Observatório Nacional de Educação Especial, que tem como foco a produção de estudos integrados sobre o programa de implementação das Salas de Recursos Multifuncionais (SRM) tendo em vista a política da inclusão escolar. O objetivo do presente estudo é o de analisar a produção científica produzida na forma de teses e dissertações que abordam o funcionamento das salas de recursos. Para tanto, foi realizada uma busca no banco de teses e dissertações da Capes com os seguintes descritores: atendimento educacional especializado, sala de recursos e sala de recursos multifuncionais, que resultou em 33 trabalhos encontrados sobre o tema. Os resultados indicam que há possibilidades e problemas nesses serviços, e que as SRM, pode ser um recurso, mas que sozinha não consegue responder ainda as necessidades de todos os estudantes do público alvo da Educação Especial. O presente trabalho visou contribuir com a investigação do ONEESP e consequentemente, com dados importantes sobre o funcionamento das salas de recursos no país, possibilitando conhecer como este ambiente vem se configurando e sendo apresentado nas pesquisas acadêmicas, como também para a construção do estado da arte sobre $\mathrm{o}$ atendimento educacional especializado nas salas de recursos multifuncionais

PALAVRAS-CHAVE: Educação Especial. Atendimento educacional especializado. Sala de recursos.

RESUMEN: El presente trabajo pretende contribuir a las investigaciones del Observatorio Nacional de la educación especial, que se centra en la producción de estudios integrados en el programa de aplicación de recurso multifuncional aulas (SRM) en vista de la política de la inclusión escolar. El objetivo del presente estudio es analizar la literatura científica producida en forma de tesis y disertaciones que cubre la operación de salas de recurso. Se realizó una búsqueda en Banco de tesis y disertaciones de capas con las siguientes palabras clave: sala de recursos educativos, especializados y sala de recursos múltiples funciones, que resultó en 33 obras encontradas sobre el tema. Los resultados indican que hay posibilidades y problemas en estos servicios, y que el SRM puede ser un recurso, pero que solo no puede responder a las necesidades de todos los estudiantes del público objetivo de la educación especial. El presente trabajo pretende contribuir a la investigación de ONEESP y, en consecuencia, con datos importantes sobre el funcionamiento de los

\footnotetext{
${ }^{1}$ Departamento de Psicologia, Programa de Pós-Graduação em Educação Especial

2 epartamento de Psicologia, Programa de Pós-Graduação em Educação Especial
} 
recursos en el país, haciendo posible conocer este entorno ha sido ajuste para arriba y ser destacado en investigación académica, pero también para la construcción del estado del arte sobre el servicio educativo especializado en las aulas recurso multifuncional

PALABRAS CLAVE: Especial educación. Atención educativa especializada. Sala de recursos.

ABSTRACT: The aim of this study analysis was of scientific production in the form of theses and dissertations related to resource rooms operation. For that, it was done a research in Capes theses and dissertations database with the following descriptors: specialized educational services, resource rooms and multifunctional resource rooms, which resulted in 33 studies published on this subject. The results indicate that there are possibilities and problems in these services, and that the MRR can be a resource, but by itself cannot attend the needs of all Special Education target audience students. This study aimed to contribute to the investigation of the National Centre for Special Education and consequently with important data about resource rooms operation in the country, making it possible to know how this environment has represented and being presented in academic research, as also for to build the state of the art on the specialized educational services in multifunctional resource rooms.

KEYWORDS: Special Education. Specialized educational services. Resource room.

\section{Introdução}

A Constituição Federal de 1988 (BRASIL, 1988) estabelece que a educação é um direto de todos, e que um dos princípios que deverão reger o ensino é a igualdade de condições de acesso e permanência na escola. Este mesmo documento coloca que deverá ser ofertado aos alunos com deficiências, o atendimento educacional especializado (AEE). Atendimento Educacional Especializado (AEE), que é definido como sendo "um conjunto de atividades, recursos de acessibilidade e pedagógicos organizados institucionalmente, prestado de forma complementar ou suplementar à formação dos alunos no ensino regular" (Brasil/SEESP,2008, § 1). No entanto, sabe-se que os alunos público-alvo da educação especial (pessoas com deficiências, transtornos globais do desenvolvimento e altas habilidades/superdotação) enfrentaram muitas dificuldades para, de fato, acessar e permanecer no ambiente escolar.

Lei de Diretrizes e Bases da Educação Nacional 9.394/96 (BRASIL, 1996) previu o dever de oferta do AEE aos alunos público-alvo da educação especial, preferencialmente na rede comum de ensino, quando fosse necessário para atender às necessidades específicas do aluno, sendo que a oferta destes serviços deveria ser iniciada logo na educação infantil. No entanto, foi apenas em 2007, com a Portaria Normativa $\mathrm{n}^{\circ} 13$ de 24 de abril do referido ano, que o Governo dispôs de fato sobre a 
criação do Programa de Implementação das Salas de Recursos Multifuncionais (BRASIL, 2007).

As salas de recursos multifuncionais (SRM) devem oferecer recursos e apoio pedagógico os estudantes. Estas salas se caracterizam como um espaço dotado de equipamentos de informática, ajudas técnicas, materiais pedagógicos e mobiliários adaptados para suprir as necessidades dos alunos (BRASIL, 2007).

De acordo com Anjos (2011), as salas de recursos foram criadas na década de 80 e eram inicialmente voltadas para o atendimento de pessoas com algum tipo de deficiência que frequentavam o ensino regular, a fim de se configurar como uma alternativa ao processo de segregação que essas pessoas viviam. De acordo com Baptista (2011), a SRM é atualmente compreendida como sendo o lócus preferencial para o atendimento de alunos público-alvo da educação especial.

Levando em consideração a necessidade de adaptações curriculares para propor um ensino para todos, Oliveira e Leite (2011) realizaram um estudo a fim de caracterizar o funcionamento de uma SRM e realizar intervenção junto a uma professora especialista para auxiliá-la na implementação de ações educacionais. Para tanto, foram realizadas observações com auxílio de um roteiro, leitura das fichas dos alunos e documentos fornecidos pela professora e entrevista antes e após a intervenção para tomar conhecimento dos efeitos resultantes da mesma. Foram realizados quatro encontros entre a pesquisadora e a professora a fim de discutirem sobre as práticas pedagógicas e implementação dos procedimentos a serem utilizados para o documento individual de adaptações curriculares. Os resultados das análises e observações permitiram perceber que, mesmo cumprindo os requisitos legais, a função da sala de recursos, população atendida e características do atendimento pedagógico divergem do estabelecido por Leis e Decretos. De acordo com as autoras, percebeu-se que a intervenção foi efetiva, pois colaborou para que a professora refletisse sobre sua atuação na sala de recursos, colaborando para um ensino efetivo dos alunos atendidos. Ressaltase que o professor especialista tem dúvida em relação ao seu papel, apresenta dificuldades e se vê sozinho no atendimento aos alunos na sala de recursos.

Sabe-se que o Brasil tem muito a avançar em relação à educação, principalmente, quando se trata da educação do público-alvo da educação especial. A produção científica na área de Educação Especial vem aumentando consideravelmente, porém, parece que o conhecimento produzido pelas pesquisas não têm gerado impacto na construção e na prática das políticas educacionais desta área (MENDES, 2010). 
Assim, nota-se que as SEM, que deveriam ser um de muitos serviços oferecidos para essa população, acabam se tornando o único serviço disponível. Diante desta realidade, surgem inúmeras questões a respeito do seu funcionamento, e buscando refletir e encontrar meios para a melhoria de tal atendimento, foi desenvolvido um projeto de pesquisa pelo Observatório Nacional de Educação Especial (ONEESP) intitulado "estudo em rede nacional sobre o programa de implantação das SRM nas escolas comuns". O presente trabalho está vinculado ao ONEESP, e buscou contribuir para construir o estado da arte sobre essa temática e colaborar com a ampliação e avanço do conhecimento sobre o funcionamento das SRM.

Os estudos sobre as salas de recursos são investigados sob a ótica do Oneesp em três eixos: funcionamento das salas de recursos, formação de professores e avaliação dos alunos. No presente trabalho será dada ênfase aos trabalhos que discorrem sobre o funcionamento das salas de recursos. Acredita-se que a análise da produção científica é de suma importância para qualquer área do conhecimento, pois permite a identificação dos temas já estudados, daqueles que necessitam serem mais explorados, além de proporcionar uma reflexão sobre elementos, tais como revisões de teorias e definições políticas (NORONHA et. al, 2006).

De acordo com Nunes Sobrinho (1997) há necessidade de revisões críticas do saber produzido e das práticas correntes de educação para o público-alvo da educação especial. Entende-se que teses e dissertações se constituem como importantes fontes de pesquisa a respeito da educação para alunos da Educação Especial, como também de verificar o avanço (ou não) das políticas públicas direcionadas a este público, e se de fato são concretizadas. Além disso, a avaliação sistemática da produção científica colabora para proceder-se a diversos tipos de análise e decisões, e no caso da Educação Especial, vêm colaborando para a análise crítica e reflexiva sobre a área. Diante do exposto a respeito da atual Política Nacional da Educação Especial e juntamente com os objetivos do ONEESP, percebe-se uma necessidade de esmiuçar o que tem sido publicado em teses e dissertações na área. Sendo assim, o objetivo do presente estudo é o de analisar a produção científica, produzida em nível de teses e dissertações, que abordam o funcionamento das salas de recursos.

\section{Desenvolvimento}


$\mathrm{Na}$ presente pesquisa foram utilizadas como fonte de dados teses e dissertações indexadas no banco da Capes sobre AEE, sob o eixo temático de funcionamento das salas de recursos/salas de recursos multifuncionais, publicadas entre os anos de 2002 a 2012. A data foi escolhida levando em consideração que, mesmo antes da publicação da Portaria $n^{\circ} 3$ de 2007, a qual dispõe sobre a implantação da sala de recursos como apoio à oferta do atendimento educacional especializado, as salas de recursos já existiam e as análises podem colaborar para tomar conhecimento se ocorreram mudanças no seu funcionamento após a publicação da referida Portaria.

\section{Procedimento de coleta e análise de dados}

Primeiramente, foi realizada a busca pelas teses e dissertações que estão indexadas no site da Capes. Tal busca foi orientada pelas palavras-chave: atendimento educacional especializado, sala de recursos e sala de recursos multifuncionais. Para delimitar a revisão, foi dada ênfase às dissertações e teses que se enquadravam no eixo temático 'funcionamento das salas de recursos'.

Foram encontrados 33 trabalhos, sendo duas teses de doutorado e 31 dissertações de mestrado. Após a busca no site da Capes foi realizada a busca pelos trabalhos na íntegra, uma vez que o banco de dados da Capes fornece apenas o resumo da tese ou dissertação. Estes trabalhos foram procurados nos sites das bibliotecas das Universidades onde foram realizados. No entanto, mesmo com a obrigatoriedade das Universidades disponibilizarem os trabalhos acadêmicos em formato eletrônico a partir de 2001/2002, foram encontrados 27 trabalhos na íntegra sobre o tema

A análise das pesquisas foi feita seguindo o Roteiro de Análises de Teses e Dissertações (MENDES; FERREIRA; NUNES; 2002). Este instrumento é dividido em três partes, sendo que a primeira é voltada para a identificação da tese e dissertação (título, autor, orientador, instituição-programa e o ano da defesa). A segunda parte do roteiro se refere à análise descritiva da dissertação/tese, que busca informações sobre tema principal e secundário, objetivos, referencial teórico, fonte de dados, população, local, metodologia, resultados e conclusões encontradas, as principais referências bibliográficas utilizadas e as implicações teóricas para pesquisas futuras. Por fim, a terceira parte do roteiro visa à análise crítica das teses e dissertações, como a qualidade da revisão de literatura, consonância teórico-metodológica, concepção do autor sobre deficiência e análise pragmática da dissertação/tese. Após a leitura dos trabalhos, foi 
criado um banco de dados a fim de agrupá-los em categorias estabelecidas pelo instrumento.

\section{Resultados e Discussão}

Dos trabalhos encontrados na íntegra, foi possível compilar 27 deles (82\%), sendo destes, duas teses de doutorado. A maioria das produções acadêmicas analisadas se concentrou na região Sul, representando $44,5 \%$, sendo estes trabalhos defendidos na Universidade Estadual de Maringá, Universidade Federal do Rio Grande do Sul e Universidade Federal do Paraná. O Sudeste foi a segunda região com maior número de produções, com um total de aproximadamente 30\%. As universidades dessa região com trabalhos sobre o tema foram: Universidade Federal de São Carlos, Universidade Estadual do Rio de Janeiro, Universidade do Estado do Espírito Santo, Universidade Estadual Paulista e Metodista de São Paulo. As regiões Centro-Oeste e Nordeste tiveram quatro e três trabalhos publicados, respectivamente, e a região Norte, apenas um. As teses de doutorado são oriundas da região Sudeste (Universidade Federal de São Carlos) e Centro-Oeste (Universidade do Mato Grosso do Sul). A figura 1 apresenta o número de publicações por ano:

Figura 1: Número de publicações por ano

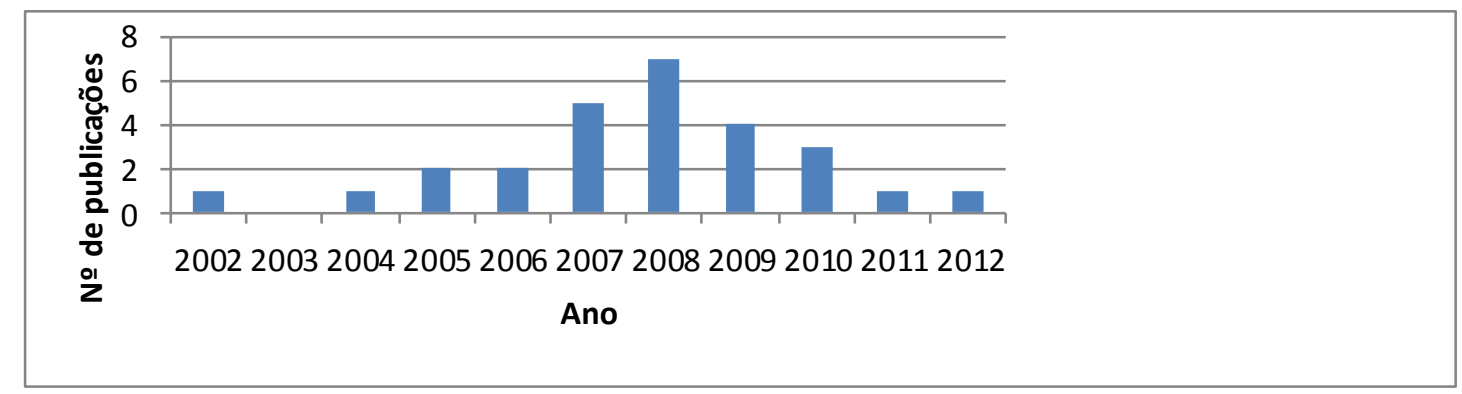

Fonte: Autoria própria.

Nota-se que o ano de 2008 foi o que apresentou maior número ( $\mathrm{N}=7$ ) de trabalhos de dissertações ou teses sobre funcionamento das salas de recursos, seguido dos anos de 2007 (N=5) e 2009 (N=4). Percebe-se que o número de publicações teve um grande aumento no ano de 2008 e depois declinou. Tal dado pode indicar que a Portaria n 13 de 2007 (BRASIL, 2007), que dispõe sobre o Programa de Implantação 
das Salas de Recursos Multifuncionais, não impactou em pesquisas acadêmicas focando este serviço.

A população alvo mais investigada nos trabalhos foram alunos público-alvo da educação especial em geral $(\mathrm{N}=7)$, ou seja, as pesquisas não se restringiam a uma única deficiência e sim tinham como foco todo o alunado atendido pelas salas de recursos. Em seguida, têm-se os estudos que direcionaram seu interesse à Deficiência Intelectual $(\mathrm{N}=5)$. Alunos com deficiência auditiva, altas habilidades/superdotação e deficiência intelectual ou dificuldades de aprendizagem foram investigadas em duas dissertações cada. O baixo índice de pesquisas direcionadas a necessidades específicas é alarmante. Uma hipótese que pode ser levantada em relação ao público-alvo dos trabalhos pode estar relacionada ao fato das salas de recursos investigadas serem categoriais (direcionadas ao atendimento de uma necessidade específica) ou não, pois em muitas cidades há uma distribuição diferenciada dos alunos público-alvo nas salas de recursos, havendo salas direcionadas a todos os alunos público-alvo da educação especial e aquelas que direcionam o atendimento para alunos com necessidades específicas. No entanto, nem todos os estudos deixam claro se as salas são ou não categoriais.

No que se refere à relação entre o número de defesas por ano e a população alvo investigada, foi possível perceber que os trabalhos que tiveram como alvo os alunos com dificuldades de aprendizagem, foram defendidos em 2005, 2006 e 2008, e a categoria de alunos com deficiência intelectual ou dificuldades de aprendizagem começou a ser investigada a partir de 2007 . Este dado pode estar relacionado ao fato de que muitas vezes o aluno não tem um diagnóstico clínico, mas apresenta dificuldades de aprendizagem, ou até mesmo a falta de clareza sobre a diferença entre deficiência intelectual e dificuldades de aprendizagem e de sistematização na avaliação e encaminhamento dos alunos, elevando o número de alunos encaminhados para as salas de recursos (OLIVEIRA, 2004; GIORGI, 2007; SILVA, 2009).

Em relação aos temas principais abordados nas pesquisas, percebe-se que houve certo predomínio dos temas ensino/aprendizagem e integração/inclusão nos trabalhos analisados. Tais temas podem ter sido predominantes devido ao fato de que o foco das salas de recursos é a aprendizagem dos alunos que as frequentam e este ambiente é uma estratégia para que os alunos público-alvo da educação especial frequentem a escola regular e tenham suas necessidades atendidas de forma satisfatória.

Fazendo um paralelo entre o tema da pesquisa e o público-alvo investigado, nota-se que o tema ensino-aprendizagem teve como população alvo, em sua maioria, 
alunos com dificuldades de aprendizagem e alunos com deficiência intelectual. Pode-se levantar a hipótese de que essa relação ocorreu pois o ensino para alunos com dificuldades de aprendizagem, assim como para os com deficiência intelectual, necessita de maior investigação, devido ao fato de não haver clareza por parte dos profissionais da educação de como este alunado lida com o saber e a produção do conhecimento, além de documentos que versam sobre o AEE para alunos com deficiência intelectual não deixarem claro qual a função deste serviço (VELTRONE; MENDES, 2011).

Os temas atitude/percepção e Políticas em Educação Especial representaram $19 \%$ das publicações cada categoria, sendo que tais estudos buscaram compreender a percepção que professores, pais e os próprios alunos das salas de recursos têm a respeito desse serviço, de como é constituído, como funciona, pois é importante verificar se os pais, por exemplo, conhecem o atendimento que seus filhos recebem, e o que entendem por esse tipo de serviço, se é visto como uma forma de inclusão escolar e reforço. Investigar as Políticas da Educação Especial e, mais especificamente, as direcionadas às salas de recursos é de suma importância para tomar conhecimento do que está sendo previsto em lei para a educação dos alunos público-alvo da educação especial, as mudanças e avanços que vêm ocorrendo.

No que se refere à metodologia utilizada nas pesquisas sobre as salas de recursos, percebeu-se que a metodologia descritiva predominou em praticamente metade dos estudos analisados. Segundo Oliveira (2010), essa metodologia de pesquisa tem por objetivo analisar fatos ou fenômenos, descrevendo detalhadamente como se apresentam, se caracterizando como "uma análise em profundidade da realidade pesquisada" (p. 68). De forma geral, estes estudos utilizaram entrevistas semiestruturadas e observação nas salas de recursos com o intuito de tomar conhecimento do funcionamento da mesma. Estudos de campo/caso utilizando observação dos fatos para tomar conhecimento representaram 18,5\% da metodologia utilizada nas pesquisas analisadas. Pesquisa-ação, histórica, etnográfica e experimental totalizaram oito trabalhos.

Do total de trabalhos analisados, $56 \%$ adotaram uma visão social da deficiência e $44 \%$ abordaram a deficiência com um enfoque psicoeducacional. De acordo com Nunes, Ferreira, Glat e Mendes (1999, p. 120) a visão social da deficiência "entende a deficiência como um fenômeno de ordem social e enfatiza as circunstâncias sociais em que alguém é identificado e tratado como deficiente”, enquanto que a concepção psicoeducacional olha a deficiência se baseando em teorias psicológicas de 
aprendizagem e desenvolvimento humanos na sua relação com o processo educacional. O trabalho de Piccolo e Mendes (2013) reflete sobre a questão de a deficiência, muitas vezes, não ser tratada sob a forma social. Os dados do presente trabalho mostram que a concepção social foi adotada na maioria dos trabalhos, podendo indicar uma possível mudança de visão sobre a deficiência. Na relação entre tema e concepções, notou-se que os temas integração/inclusão e políticas educacionais foram tratados predominantemente segundo a concepção social, enquanto que o tema atitude/percepção, foi tratado predominantemente sob a concepção psicoeducacional.

Em relação aos resultados encontrados nos trabalhos analisados, pôde-se perceber que em muitos casos, a sala de recursos está sendo vista como facilitadora da escolarização de alunos público-alvo da educação especial, no entanto, professores das salas de recursos não conseguem trabalhar de forma pedagógica o conteúdo para os alunos. Além disso, percebeu-se que em alguns relatos os alunos utilizam a sala de recursos para revisar a matéria dada na sala regular, levando a entender que está sendo usada como reforço escolar, indo contra o objetivo da sala de recursos segundo as recomendações oficiais (MACHADO, 2006; NOGUEIRA, 2007; ROPOLI, 2010).

Sendo assim, os estudos analisados mostram que a educação para os alunos público-alvo da educação especial ainda necessita de muitas mudanças, uma vez que foram destacados diversos aspectos negativos no que tange ao funcionamento das salas de recursos multifuncionais. Primeiramente, cabe ressaltar que os estudos mostraram que há inadequação do espaço físico para o funcionamento dessas salas, falta de acessibilidade arquitetônica e não há uma sala específica para esse atendimento, que passa a ser feito em espaços improvisados (OLIVEIRA, 2004; ALBUQUERQUE, 2008: CHIESA, 2009).

Além da inadequação física, Melo (2008) aponta que esse distanciamento também ocorre no que tange às questões pedagógicas. As salas de recursos multifuncionais devem ter acessibilidade arquitetônica para o acesso de todos os alunos, além de os professores terem formação continuada (ROPOLI, 2010). No entanto, parece que tais indicações ainda não estão sendo praticadas ou ao menos, são falhas.

Um ponto que foi bastante mencionado nos estudos foi a falta de professores capacitados e/ou especializados para o atendimento do alunado da educação especial (OLIVEIRA, 2004; REDIG, 2010), assim como a falta de troca de informações e apoio entre os professores do ensino regular e das salas de recursos, ou seja, não se constata a parceria entre eles, assim como também falta de apoio da equipe pedagógica para os 
professores das salas de recursos (OLIVEIRA, 2004; SANTOS, 2007; ALBUQUERQUE, 2008; REDIG, 2010).

A Nota Técnica 11/10 estabelece a necessidade de interação dos professores do ensino especial com os da sala de aula comum, entretanto, como os professores devem trabalhar em turnos diferentes, isso provavelmente dificulta o intercâmbio entre eles. As propostas apontadas na literatura de ensino colaborativo ou coensino, onde o professor do ensino comum e do ensino especial dividem a responsabilidade de planejar, instruir e avaliar a instrução de um grupo heterogêneo de estudantes na classe comum (MENDES; ALMEIDA; TOYODA, 2011) não aparecem nos estudos como uma prática das escolas. Embora estudos (CAPELLINI; MENDES, 2007; KEEFE; MOORE; DUFF, 2004) mostrem que esse modelo de prestação de serviços pode ser mais eficaz do que o da salas de recursos, parece que no contexto brasileiro ainda não estão dando importância a este método de trabalho.

As salas de recursos devem oferecer material diversificado para o atendimento dos alunos PAEE, no entanto, diferente do que é estabelecido, notou-se pela análise dos estudos que há escassez de material didático e equipamentos (SANTOS, 2007; BRANDÃO, 2007; ALBUQUERQUE, 2008), o que prejudica o aprendizado dos alunos com deficiência visual e altas habilidades/superdotação.

Outra questão bastante recorrente nos estudos é o fato de o atendimento em salas de recursos estar ocorrendo no mesmo turno da sala comum, sendo que, ou a professora retira o aluno da sala para receber o AEE na sala de recursos, ou a professora acompanha o aluno na sala regular (GIORGI, 2007; ARNAL, 2007). Tal fato pode estar relacionado também com o que é relatado no estudo de Melo (2008), onde há a falta de planejamento das atividades e dificuldade da professora da sala de recursos no desenvolvimento das atividades.

Santos (2007) mostrou uma realidade onde era comum os professores da sala regular não entregarem o material para os professores das salas de recursos em tempo hábil para adaptação, o que evidenciava a falta de colaboração entre os professores e o consequente comprometimento do aprendizado dos alunos que necessitassem de adequações curriculares. Além disso, os professores das salas regulares parecem não conhecer o trabalho realizado nas salas de recursos, mas reconhecem que o desempenho acadêmico dos alunos que recebem o AEE tem melhorado (TEZZARI, 2002; REDIG, 2010). Diante desses resultados é nítida a questão da importância da parceria entre 
professores do ensino regular e especial, para que ocorra de fato uma inclusão escolar dos alunos que têm necessidade de maior apoio no sistema educacional.

O fato de o AEE em salas de recursos acontecer no contra turno parece ser uma dificuldade em outros locais, assim como afirma Oliveira (2009); além disso, alunos de escolas que não possuem SR devem se direcionar a escolas próximas que ofereçam esse tipo de serviço, o que pode acabar dificultando o serviço do professor, devido à distância entre as escolas e os horários (OLIVEIRA, 2004).

Em relação às atividades que acontecem nas salas de recursos, nota-se que há repetição de conteúdos da sala regular, número excessivo de atividades propostas, professores que não conseguem organizar sequências didáticas ou planejar atividades e ainda, muitas vezes não conseguem trabalhar de forma pedagógica, priorizando a meta de dar apoio emocional e psicológico ao invés de educar (ARNAL, 2007; OLIVEIRA, 2008; ALBUQUERQUE, 2008; MELO, 2008; SILVA, 2009).

Foi possível constatar também que em alguns locais as salas de recursos têm sido utilizadas como um espaço para reforço escolar (MACHADO, 2006; OLIVEIRA, 2010). Percebe-se então que as salas de recursos parecem estar se configurando de maneira contrária ao previsto. O documento "Sala de recursos multifuncionais: espaço para atendimento educacional especializado” (BRASIL, 2006, p.15) dispõe que tal atendimento "não pode ser confundido com atividades de mera repetição de conteúdos programáticos desenvolvidos na sala de aula, mas deve constituir um conjunto de procedimentos específicos mediadores do processo de apropriação e produção de conhecimentos".

Esses achados são importantes para levantar questionamentos de como os alunos público-alvo da educação especial estão sendo escolarizados e como a educação para eles está se constituindo. Dos pontos positivos que foram possíveis levantar com a análise das pesquisas, pode-se perceber que o número de salas de recursos e de atendimentos nestas salas aumentou consideravelmente (OLIVEIRA, 2004; CORRÊA, 2012) e que a quantidade de alunos e de atendimentos realizados se encontram dentro do previsto por lei (ARNAL, 2007; SILVA, 2009).

O estudo de Prado (2006) mostrou que alunos que frequentam as salas de recursos e seus familiares estão satisfeitos, além do desempenho acadêmico destes alunos terem melhorado (BARRETO, 2008; CARNEIRO, 2009). Ao contrário de estudos que mostraram que não há parceria entre os professores do ensino regular e especial, Brandão (2007) e Silva (2009) mostram que esses professores trabalham em 
conjunto, visando a melhoria do ensino para os alunos público-alvo da educação especial.

Tezzari (2002), Albuquerque (2008) e Silva (2009) apontam que são atendidos nas salas de recursos alunos com diversos tipos de necessidades especiais, tais como aqueles com comprometimentos mais graves e os que apresentam dificuldades de aprendizagem. Ressalta-se que os estudos de Albuquerque (2008) e Silva (2009) foram realizados após a mudança da clientela atendida na educação especial, no entanto, os estudos mostram que são atendidos nas salas de recursos alunos com hiperatividade, dislexia, dificuldades de aprendizagem, problemas de comportamento e ainda muitos sem diagnóstico fechado. Nota-se, portanto, que embora o estabelecido seja de que as salas de recursos são destinadas para o atendimento de alunos com altas habilidades/superdotação, deficiências e transtornos globais do desenvolvimento, na realidade o atendimento é estendido a tantas outras especificidades.

Alguns apontamentos feitos nos estudos para a melhoria do funcionamento das salas de recursos seriam:

1) A inserção destas nas propostas pedagógicas e regimentos escolares;

2) Maior divulgação e entendimento por parte dos professores da diferença entre dificuldades de aprendizagem e deficiência intelectual;

3) Necessidade das salas de recursos funcionarem na própria escola comum do aluno, dada a proximidade e a ação dos professores que investem no atendimento a essas respostas;

4) Necessidade de a escola promover um espaço para discussão sobre essas salas, envolvendo toda a comunidade escolar e aos setores de gestão;

5) Maior investimento nos serviços oferecidos a esse alunado;

6) Focar o ensino de LIBRAS para alunos surdos e ouvintes;

7) Necessidade de trabalho colaborativo entre professores do ensino regular e sala de recursos;

8) Necessidade de um maior uso da sala de recursos pelos professores, para que a parceria com o educador especializado se concretize e possa contribuir para uma inclusão escolar efetiva (OLIVEIRA, 2004; PRADO, 2006; NOGUEIRA, 2007; REDIG, 2010).

9) No caso de alunos com altas habilidades, deve-se pensar em parcerias entre as SR e as universidades (SAKAGUTI, 2010).

Pasolini (2009) destaca que as salas de recursos têm se constituído como foco principal na escolarização de alunos público-alvo da educação especial. No entanto, sabe-se que a sala de recursos deve ser apenas um entre vários serviços de apoio que o sistema escolar deve oferecer para esse alunado. Tal consideração é reforçada pela ressalva feita por Corrêa (2012), que chama a atenção para a necessidade de analisar criticamente as políticas públicas de educação e não considerar que o atendimento 
educacional especializado nas salas de recursos seja uma única política de educação especial.

Quanto às implicações teóricas e práticas dos estudos, ou seja, as recomendações feitas por cada autor para futuras investigações, estas sugerem que:

a) Os estudos sobre atitude/percepção apontam, de forma geral, para a importância de pesquisas sobre programas de prevenção e reabilitação na área de deficiência visual no setor da saúde, assim como, de forma prática, que sejam oferecidos subsídios para os familiares de estudantes público-alvo da educação especial;

b) As pesquisas com enfoque no tema integração/inclusão sugerem a necessidade de investigar mais os estudantes do ensino fundamental que frequentam as salas de recursos, a questão do encaminhamento de alunos com dificuldades de aprendizagem para essas salas e que eles sejam feitos nas realidades mais diversificadas possíveis;

c) Pesquisas sejam conduzidas envolvendo não apenas o professor da sala de recursos, mas também a equipe pedagógica da escola, pois, como preconizam os documentos oficiais, a construção de uma educação inclusiva deve envolver a reestruturação da escola como um todo e, sendo assim, a participação da equipe diretamente responsável pelo suporte pedagógico é fundamental;

d) Investimento em pesquisas que, além do acompanhamento da proposta pedagógica desenvolvida para os alunos na sala de recursos, voltem-se para o acompanhamento da proposta que esse aluno recebe na sala de ensino comum, a fim de identificar os diferentes tipos de ajustes realizados para atender às suas necessidades no acesso ao processo educacional;

e) Revisão dos procedimentos de avaliação dos alunos;

f) Revisão do currículo nas salas de recursos, nas adaptações curriculares e inserção de conteúdos de caráter funcional e prático;

g) Os trabalhos do tema políticas em educação especial, apontam para o desenvolvimento de estudos sobre a dinâmica do funcionamento no contexto escolar e a investigação da aplicação de recursos públicos para esse fim.

\section{Conclusões}

O presente estudo buscou conhecer o que está sendo produzido em termos de conhecimento a respeito das salas de recursos multifuncionais em teses e dissertações. Com isso, foi possível um breve mapeamento das produções e as possibilidades e dificuldades do serviço de atendimento educacional especializado nas salas de recursos, podendo constatar que a realidade está distante daquilo que é estabelecido no plano legal.

Aponta-se como limitação do estudo o fato de que ainda são poucos estudos e com baixa representatividade, dada a imensidão do país e considerando que as estatísticas oficiais apontam para a existência de mais de 30 mil SRM em funcionamento no país. Além do numero pequeno de estudos ressalta-se ainda a 
dificuldade de encontrar alguns deles na íntegra. Acredita-se que pesquisas que busquem outros eixos sobre as salas de recursos também sejam interessantes para conhecer melhor a realidade desses serviços.

Ressalta-se aqui a importância de pesquisas que investiguem como está sendo realizado o atendimento educacional especializado nas salas de recursos, para que assim surjam novas propostas de adequação e melhora de ensino para os alunos público-alvo da educação especial.

\section{REFERÊNCIAS}

ALBUQUERQUE, R.A. Educação e inclusão escolar: a prática pedagógica da sala de recursos de 5' a 8' séries. 2008. 142p. Dissertação- Curso de Mestrado em Educação, Faculdade de Educação, Universidade Estadual De Maringá, Maringá.

ANJOS, I.R.S. O atendimento educacional especializado em salas de recursos. Revista FORUM IDENTIDADES, Itabaiana, v. 9, p. 3-11, 2011.

ARNAL, L.S.P. Educação escolar inclusiva: a prática pedagógica nas salas de recursos. 20071v. 133f. Dissertação- Curso de Mestrado em Educação, Faculdade de Educação, Universidade Estadual De Maringá, Maringá.

BAPTISTA, C.R. Ação pedagógica e educação especial: a sala de recursos como prioridade na oferta de serviços especializados. Revista Brasileira de Educação Especial, Marília, v.17, n.spe 1, p. 59-76, 2011.

BARRETO, L.C.D. Sala de recursos: um estudo da aprendizagem da leitura por alunos com dificuldades escolares. 2008. 136f. Dissertação- Curso de Mestrado em Educação, Faculdade de Educação, Universidade Estadual De Maringá, Maringá.

BRANDÃO, S.H.A. Alunos com altas habilidades/superdotação: o atendimento em sala de recursos no estado do Paraná. 2007. 119f. Dissertação- Curso de Mestrado em Educação, Faculdade de Educação, Universidade Estadual De Maringá, Maringá.

BRASIL. Constituição (1988). Constituição da República Federativa do Brasil. Brasília, DF: Senado Federal: Centro Gráfico, 1988. 292p.

BRASIL. Dados da Educação Especial no Brasil. Brasília: MEC/INEP, 2006.

BRASIL. Decreto $\mathbf{n}^{\circ}$ 6.571, de 17 de setembro de 2008. Dispõe sobre o atendimento educacional especializado. Presidência da República/Casa Civil/Subchefia para Assuntos Jurídicos. Brasília. 2008.

BRASIL. Lei no 9.394, de 23 de dezembro de 1996. Lei que fixa as diretrizes e bases da educação nacional. Brasília, 1996. 
BRASIL. Portaria Normativa $\mathbf{N}^{\mathbf{0}} \mathbf{1 3}$, de 24 de abril de 2007. Dispõe sobre a criação do "Programa de Implantação de Salas de Recursos Multifuncionais". 2007.

CAPELLINI, V.L.M.F.; MENDES, E.G. O ensino colaborativo: favorecendo o desenvolvimento profissional para a inclusão escolar. Educere, Cascavel v.2, n. 4, p. 113-128, 2007.

CARNEIRO, K.T.A. Cultura Surda Na Aprendizagem Matemática: o som do silêncio em uma sala de recurso multifuncional. 2009.1v. 176f. Dissertação- Curso de Mestrado em Educação e Ciências Matemáticas, Instituto de Educação Matemática e Científica, Universidade Federal Do Pará, Belém.

CHIESA, M. Implantação do Atendimento Educacional Especializado na rede municipal de ensino de Pelotas sob a perspectiva da Educação Ambiental. 2009. 106f. Dissertação- Curso de Mestrado em Educação Ambiental, Faculdade de Educação Ambiental, Universidade Federal Do Rio Grande, Rio Grande.

CORREAA, N.M. Salas de recursos multifuncionais e plano de ações articuladas em Campo Grande - MS: análise dos indicadores. 2012. 248f. Tese- Curso de Doutorado em Educação, Centro de Ciências Humanas e Sociais, Universidade Federal de Mato Grosso Do Sul, Campo Grande.

GIORGI, H.O.P. Sala de recursos em São Bernardo do Campo: possibilidades e limites do apoio educacional especializado na construção de uma escola inclusiva. 2007.107f. Dissertação- Curso de Mestrado em Educação, Faculdade de Educação e Letras, Universidade Metodista De São Paulo, São Bernardo do Campo.

KEEFE, E.B.; MOORE, V.; DUFF, F. The four "knows" of collaborative teaching. Teaching exceptional children, n. 36, v.5, p. 36-42, 2004.

MACHADO, J.M. Tomada de consciência no jogo "O caminho para o tesouro do pirata" de alunos com dificuldades de aprendizagem em fração e que freqüentam sala de recursos. 2006. 118f. Dissertação- Curso de Mestrado em Educação, Faculdade de Educação,Universidade Federal Do Paraná, Curitiba.

MELO, H.A. O acesso curricular para alunos(as) com deficiência intelectual na rede regular de ensino: a prática pedagógica na sala de recursos como eixo para análise. 2008. 159f. Dissertação- Curso de Mestrado em Educação, Faculdade de Educação, Universidade Federal Do Maranhão, São Luis.

MENDES, E.G.ALMEIDA, M.A., TOYODA, C.Y. Inclusão escolar pela via de colaboração entre educação especial e educação regular. Educar em Revista, Curitiba, n.41, p.81-93, 2011.

MENDES, E.G.; FERREIRA, J.R.; NUNES, L.R.P. Análise crítica das teses e dissertações sobre Educação Especial nas áreas de Educação e Psicologia- PRODISC IV. Relatório Final de Pesquisa. FAPESP. 2002. 
MENDES, E.G. Observatório Nacional de Educação Especial: Estudo em Rede Nacional sobre as salas de recursos multifuncionais nas escolas comuns. Material de uso do autor (2010).

NOGUEIRA, A.C.Z. Cultura, língua e valores surdos em uma escola inclusiva: a sala de recursos. 2007.155f. Dissertação- Curso de Mestrado em Educação Linguística, Universidade Federal Do Rio De Janeiro, Rio de Janeiro.

NORONHA, A.P.P.; ANDRADE, R.G.; MIGUEL, F.K.; NASCIMENTO, M.M.; NUNES, M.F.O.; PACANARO, S.J.; FERRUZZI, A.H.; SARTORI, F.A.;

TAKAHASHI, L.T.; COZZA, H.F.P. Análise de teses e dissertações em orientação profissional. Revista Brasileira de Orientação Profissional, São Paulo, v. 7, n. 2, p. 110, 2006.

NUNES, L.R.O.P.; FERREIRA, J.R.; GLAT, R.; MENDES, E.G A Pós-Graduação em Educação Especial no Brasil: análise crítica da produção discente. Revista Brasileira de Educação Especial, Marília, v.3, nº 5, p. 113-126, 1999.

NUNES SOBRINHO, F.P. Paradigmas da Educação Especial: Uma responsabilidade compartilhada. Revista Brasileira de Educação Especial, Marília, v. 4, n. 06, p. 29-40, 1997.

OLIVEIRA, F.M.S.G. de. As salas de recursos como apoio pedagógico especializado - À Educação Escolar do deficiente mental. 2004. 139f. Dissertação- Curso de Mestrado em Educação, Faculdade de Educação, Universidade Federal De Mato Grosso Do Sul, Campo Grande.

OLIVEIRA, G.P. Intervenção pedagógica individualizada para alunos com deficiência intelectual: ensino de leitura em salas de recursos. 2010. 204f. Tese- Curso de Doutorado em Educação Especial, Centro de Educação e Ciências Humanas, Universidade Federal De São Carlos, São Carlos.

OLIVEIRA, L.V.de. Sala de recursos e o desenvolvimento da linguagem escrita. 2009.130f. Dissertação- Curso de Mestrado em Educação, Faculdade de Educação, Universidade Estadual De Maringá, Maringá.

OLIVEIRA, M.A.; LEITE, L.P. Educação Inclusiva: análise e intervenção em sala de recursos. Paidéia, Ribeirão Preto, v. 21, n. 49, p. 197-205, 2011.

OLIVEIRA, M.A. de. Educação Inclusiva: uma análise crítica da prática pedagógica de uma professora de sala de recursos. 2008. 130f. Dissertação- Curso de Mestrado em Psicologia do Desenvolvimento e Aprendizagem, Faculdade de Ciências, Universidade Estadual Paulista Júlio De Mesquita Filho, Bauru.

OLIVEIRA, M.M. Como fazer pesquisa qualitativa. Petrópolis: Vozes, 2010.

PASOLINI, M.S. Análise do atendimento da educação especial no municipío de Colatina/ES: construindo um olhar na perspectiva inclusiva. 2008. 116f. DissertaçãoCurso de Mestrado em Educação, Faculdade de Educação, Universidade Federal Do Espírito Santo, Vitória. 
PICCOLO, G.M.; MENDES, E.G. Contribuições a um pensar sociológico sobre a deficiência. Educação e Sociedade, Campinas, v. 34, n. 123, p. 459-475, 2013.

PRADO, L. S. Sala de recursos para deficientes visuais: um itinerário, diversos olhares. 2006. 198f. Dissertação- Curso de Mestrado em Educação, Faculdade de Educação, Universidade De São Paulo, São Paulo.

REDIG, A.G. Ressignificando A Educação Especial No Contexto Da Educação Inclusiva: A Visão De Professores Especialistas. 2010.184f. Dissertação- Curso de Mestrado em Educação, Faculdade de Educação, Universidade Do Estado Do Rio De Janeiro, Rio de Janeiro.

ROPOLI, E.A. A Educação Especial na Perspectiva da Inclusão Escolar: a escola comum inclusiva. Brasília: Ministério da Educação, Secretaria de Educação Especial; Fortaleza: Universidade Federal do Ceará, 2010.

SAKAGUTI, P.M.Y. Concepções De Pais Sobre As Altas Habilidades/Superdotação Dos Filhos Inseridos Em Atendimento Educacional Especializado. 2010. 130f. Dissertação- Curso de Mestrado em Educação, Faculdade de Educação, Universidade Federal Do Paraná, Curitiba.

SANTOS, R. N. dos. Políticas públicas de apoio à inclusão educacional: um estudo sobre a articulação entre o centro de apoio pedagógico ao deficiente visual - CAP e a Escola. 2007. 192f. Dissertação- Curso de Mestrado em Educação e Contemporaneidade, Faculdade de Educação e Contemporaneidade, Universidade Do Estado Da Bahia.

SILVA, R.S. da. Sala de recursos como apoio especializado a alunos com necessidades educacionais especiais: um estudo em escolas estaduais. 2009.103p. Dissertação- Curso de Mestrado em Distúrbios do Desenvolvimento, Universidade Presbiteriana Mackenzie, São Paulo.

TEZZARI, M.L. A SIR chegou... "Sala de Integração e Recursos e a inclusão na Rede Municipal de Ensino de Porto Alegre” 2002. 182f. Dissertação- Curso de Mestrado em Educação, Faculdade de Educação, Universidade Federal do Rio Grande do Sul, Porto Alegre.

VELTRONE, A.A; MENDES, E.G. Descrição das propostas do Ministério da Educação na avaliação da deficiência intelectual. Paidéia, Ribeirão Preto, v. 21, n. 50, p. 413-421, 2011.

\section{Como referenciar este artigo}

FANTINATO, Aline Costa.; MENDES, Enicéia Gonçalves. Análise da produção científica em dissertações e teses com foco no funcionamento das salas de recursos. Revista Ibero-Americana de Estudos em Educação, Araraquara, v. 11, n. 4, p. 20872103, 2016. Disponível em: <http://dx.doi.org/10.21723/riaee.v11.n4.8182>. E-ISSN: 1982-5587.

Submetido em: outubro/2015

Aprovação final em: outubro/2016 